\title{
PENGARUH DISIPLIN DAN MOTIVASI TERHADAP KINERJA KARYAWAN PADA CV. INDAH USAHA MANDIRI PALEMBANG
}

\author{
Haikal \\ Dosen PNSD Pada Fakultas Ekonomi Universitas Palembang
}

\begin{abstract}
ABSTRAK
Tujuan penelitian ini adalah untuk mengetahui pengaruh disiplin dan motivasi terhadap kinerja karyawan pada CV. Indah Usaha Mandiri Palembang. Populasi yang dimaksud dalam penelitian ini adalah seluruh karyawan yang bekerja pada $\mathrm{CV}$. Indah Usaha Mandiri Palembang berjumlah 46 orang.

Bedasarkan hasil penelitian diperoleh nilai t-hitung disiplin (X1) sebesar 4,573 dan thitung motivasi (X2) sebesar 18,511 serta t-tabel 2,016, yang berarti nilai t-hitung lebih besar dari nilai t-tabel, maka pengaruh disiplin (X1) dan motivasi (X2) terhadap kinerja karyawan (Y) pada CV. Indah Usaha Mandiri Palembang secara parsial berpengaruh. Sedangkan pada hasil uji f diperoleh nilai f-hitung sebesar 20,384 dan f-tabel sebesar 3,214 yang berarti nilai f-hitung lebih besar dari f-tabel, maka variabel disiplin (X1) bersama-sama variabel motivasi (X2) secara simultan berpengaruh terhadap kinerja karyawan (Y) pada pada CV. Indah Usaha Mandiri Palembang. Nilai koefisien determinasi $\left(\mathrm{R}^{2}\right)$ diperoleh 0,905 atau 90,5\%, berarti pengaruh dari variabel independen terhadap variabel dependen, disiplin (X1) dan motivasi (X2), terhadap kinerja karyawan (Y) pada CV. Indah Usaha Mandiri Palembang sebesar $90,5 \%$, sedangkan sisanya $9,5 \%$ dipengaruhi oleh variabel lain yang tidak dibahas dalam penelitian ini.
\end{abstract}

\section{Kata kunci: disiplin, kinerja, dan motivasi.}

\section{PENDAHULUAN}

\section{1 . Latar Belakang Masalah}

Persaingan dalam dunia kerja yang semakin meningkat, memacu perusahaan untuk terus meningkatkan kinerja sehingga dapat menciptakan suatu produk atau jasa yang bermanfaat bagi masyarakat.Untuk menciptakan suatu produk atau jasa yang bermanfaat tentunya diperlukan tenaga kerja yang benar-benar memiliki kemampuan dan bersemangat dalam berkerja. Ada banyak faktor yang mempengaruhi kinerja karyawan, diantaranya adalah disiplin sebagai langkah untuk mengontrol jalannya kegiatan dalam mencapai tujuan dan kompensasi sebagai pemacu semangat kerja karyawan. Dalam suatu instansi atau perusahaan mungkin akan timbul permasalahan-permasalahan yang tidak bisa dipastikan walaupun sudah direncanakan dengan sebaik-baiknya.

Sumber daya manusia yang dalam hal ini adalah para karyawan pada CV. Indah Usaha Mandiri Palembang, tentunya berusaha bekerja dengan kemampuan yang mereka miliki agar dapat mencapai kinerja yang diinginkan. Rasa aman akan suasana kerja yang mampu mendorong karyawan untuk lebih berdedikasi tinggi dalam menyelesaikan tugas yang diberikan oleh pimpinan baik suasana aman sebelum kerja, saat kerja maupun setelah kerja. Kondisi kerja yang aman semacam ini, serta didukung rekan kerja yang dapat diajak untuk bekerja sama dalam berbagai aktifitas merupakan keinginan dari setiap 
karyawan di suatu organisasi. Dengan situasi semacam itu diharapkan para karyawan dapat bekerja secara maksimal dan senang terhadap pekerjaan yang dilakukannya.

Karyawan tidak hanya secara formalitas bekerja ditempatnya bekerja, tetapi harus mampu merasakan dan menikmati pekerjaannya, sehingga ia tidak akan merasa bosan dan lebih tekun dalam beraktifitas. Para karyawan akan lebih senang dalam bekerja apabila didukung oleh berbagai situasi yang kondusif, sehingga dapat mengembangkan keterampilan yang dimilikinya.

Disiplin adalah kesadaran dan kesediaan seseorang menaati semua peraturan perusahaan dan norma-norma sosial yang berlaku. Adapun arti kesadaran adalah sikap seseorang yang secara sukarela menaati semua peraturan dan sadar akan tugas dan tanggung jawabnya. Sedangkan arti kesediaan adalah suatu sikap, tingkah laku, dan perbuatan seseorang yang sesuai dengan peraturan perusahaan baik yang tertulis maupun tidak (Hasibuan, 2016 :108).

Kegiatan pendisiplinan yang dilaksanakan untuk mendorong para karyawan agar mengikuti berbagai standar dan aturan, sehingga penyelewenganpenyelewengan dapat dicegah dan juga mendorong karyawan untuk datang tepat pada waktu. Jika karyawan datang tepat waktu dan melaksanakan tugas sesuai dengan tugas yang diembannya dan taat pada peraturan yang ditetapkan maka diharapkan kinerja karyawan meningkat.

Selain disiplin kepada karyawan juga harus diberikan motivasi karena pada hakikatnya pemberian motivasi adalah untuk mendorong para karyawan bekerja lebih baik dengan penuh dedikasi dan disiplin tinggi. Dengan motivasi timbul suatu keyakinan bahwa dengan bekerja baik maka kinerja karyawan akan meningkat.

Berdasarkan dari uraian tersebut dapat dikatakan bahwa untuk meningkatkan kinerja karyawan, maka masalah disiplin dan motivasi perlu diperhatikan pimpinan, agar karayawan tersebut tetap bekerja dengan baik dan selalu memberikan prestasi yang terbaik bagi CV. Indah Usaha Mandiri Palembang.

\section{2 . Perumusan Masalah}

Dalam penelitian ini dapat diidentifikasikan masalah-masalah yang berhubungan dengan karyawan $\mathrm{CV}$. Indah Usaha Mandiri Palembang adalah :

a. Apakah disiplin kerja berpengaruh terhadap kinerja karyawan $\mathrm{CV}$. Indah Usaha Mandiri Palembang?

b. Apakah motivasi berpengaruh terhadap kinerja karyawan $\mathrm{CV}$. Indah Usaha Mandiri Palembang?

c. Apakah disiplin kerja dan motivasi berpengaruh secara simultan terhadap kinerja karyawan $\mathrm{CV}$. Indah Usaha Mandiri Palembang?

\subsection{Tujuan Penelitian}

a. Tujuan dari penelitian ini adalah untuk mengetahui dan menganalisis pengaruh disiplin terhadap kinerja karyawan CV. Indah Usaha Mandiri Palembang

b. Tujuan dari penelitian ini adalah untuk mengetahui dan menganalisis pengaruh motivasi terhadap kinerja karyawan CV. Indah Usaha Mandiri Palembang

c. Tujuan dari penelitian ini adalah untuk mengetahui dan menganalisis pengaruh disiplin dan motivasi secara simultan terhadap kinerja karyawan CV. Indah Usaha Mandiri Palembang 


\subsection{Kerangka Pikir}

Kerangka pikir adalah sebuah kerangka pemikiran yang didapat dari hasil sintesa penulis terhadap teori atau konsepkonsep serta hasil penelitian terdahulu yang banyak dilakukan. Maka dapatlah diketahui Variabel Independen yaitu Disiplin (X1)n dan Motivasi (X2) karyawan pada CV. Indah Usaha Mandiri Palembang berpengaruh dengan variabel dependen atau Kinerja (Y) yang dapat dilihat pada skema hubungan variabel pada gambar berikut

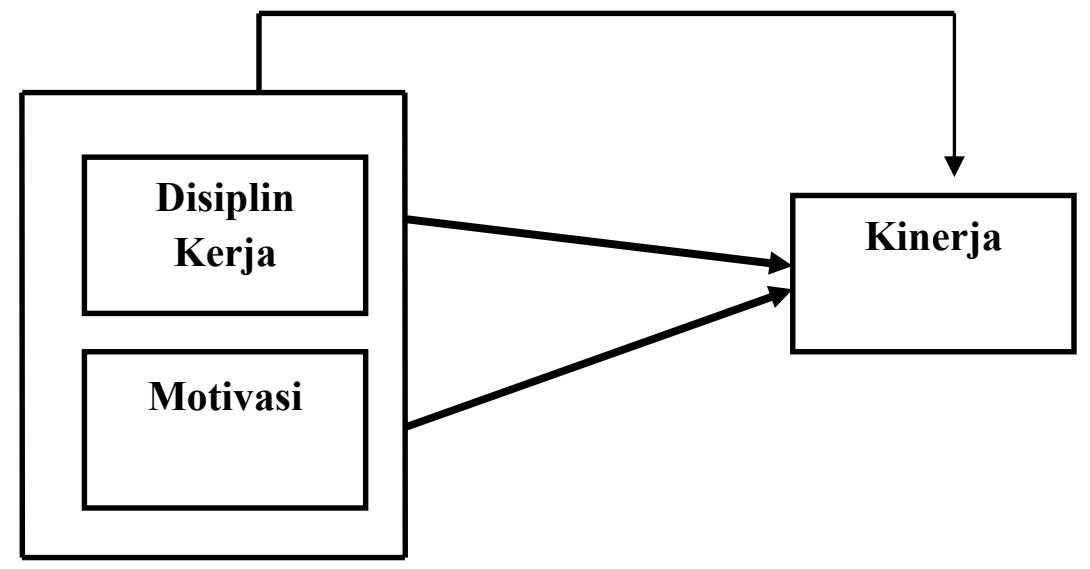

Gambar 1. Kerangka Pikir Penelitian Skema Hubungan Variabel

\section{OBJEK DAN METODOLOGI PENELITIAN}

\subsection{Definisi Operasional}

Definisi operasional dari masingmasing variabel digunakan untuk menjelaskan variabel yang diidentifikasi sebagai upaya pemahaman dalam penelitian. Dalam penelitian ini definisi operasional variabel adalah sebagai berikut:

\section{a. Variabel bebas $\left(\mathbf{X}_{1}\right)$ yaitu Disiplin Kerja}

Disiplin kerja adalah sikap ketaatan dan kesetiaan karyawan terhadap peraturan tertulis / tidak tertulis yang tercermin dalam bentuk tingkah laku dan perbuatan untuk mencapai suatu tujuan tertentu.

\section{b. Variabel bebas $\left(\mathrm{X}_{2}\right)$ yaitu Motivasi}

Motivasi merupakan dorongan atau daya yang timbul dari dalam diri sendiri, tanpa ada paksaan dari siapapun untuk melakukan suatu pekerjaan.

\section{c. Variabel tidak bebas (Y) yaitu Kinerja Karyawan}

Kinerja karyawan adalah hasil kerja yang dapat dicapai oleh karyawan dalam rangka melaksanakan tugas dan tanggung jawabnya.

\subsection{Populasi dan Sampel}

Populasi dalam penelitian ini terdiri dari para karyawan $\mathrm{CV}$. Indah Usaha Mandiri Palembang yang berjumlah 46 orang. Mengingat terbatasnya atau kecilnya jumlah populasi, maka penelitian ini akan dilakukan dengan metode sensus, dimana seluruh populasi akan dijadikan sampel dalam penelitian ini, sehingga hasil penelitiannya dapat menjelaskan secara lebih akurat. 


\subsection{Skala Pengukuran Variabel}

Skala pengukuran variabel yang dipergunakan penelitian ini adalah dengan menggunakan Skala Likert. Skala Likert digunakan untuk mengukur sikap, pendapat dan persepsi seseorang / kelompok tentang fenomena sosial. Dalam melakukan penelitian terhadap variabelvariabel yang akan diuji, pada setiap jawaban akan diberi skor. Skor yang diberikan adalah sebagai berikut:

Tabel 2.1

Instrumen Skala Likert

\begin{tabular}{|c|l|c|}
\hline NO & \multicolumn{1}{|c|}{ PERNYATAAN } & SKOR \\
\hline 1 & Sangat Setuju (SS) & 5 \\
\hline 2 & Setuju (S) & 4 \\
\hline 3 & Kurang Setuju (KS) & 3 \\
\hline 4 & Tidak Setuju (TS) & 2 \\
\hline 5 & Sangat Tidak Setuju (STS) & 1 \\
\hline
\end{tabular}

\section{HASIL PENELITIAN DAN PEMBAHSAN}

\section{1 . Uji Instrumen}

\section{a. Uji Validitas}

Dari hasil pengujian validitas dengan menggunakan SPSS 25 (hasil perhitungan dapat dilihat dalam lampiran) diperoleh koefisien validitas dari setiap item dalam kuesioner, maka hasilnya terlihat dalam tabel berikut, untuk variabel disiplin kerja $\left(\mathrm{X}_{1}\right)$, hasil dari validitas yang telah dilakukan menunjukkan bahwa dari seluruh item (6 butir) pertanyaan dalam kuesioner yang digunakan sebagai alat ukur ternyata semua item pertanyaan memiliki nilai diatas batas kritis yang ditentukan, sehingga dinyatakan valid. Secara terperinci nilai dari masing-masing item dapat ditunjukkan tabel

ini:

Tabel 3.1

Hasil Uji Validitas Disiplin Kerja $\left(\mathbf{X}_{1}\right)$

\begin{tabular}{|c|c|c|}
\hline $\begin{array}{c}\text { Butir } \\
\text { pertanyaan }\end{array}$ & $\begin{array}{c}\text { Corrected } \\
\text { Item total Correlation }\end{array}$ & Status \\
\hline Butir 1 & 0,738 & Valid \\
\hline Butir 2 & 0,637 & Valid \\
\hline Butir 3 & 0,752 & Valid \\
\hline Butir 4 & 0,621 & Valid \\
\hline Butir 5 & 0,791 & Valid \\
\hline Butir 6 & 0,637 & Valid \\
\hline
\end{tabular}

Sumber : Data diolah 2020

Untuk variabel motivasi $\left(\mathrm{X}_{2}\right)$, hasil dari uji validitas yang telah dilakukan menunjukkan bahwa dari seluruh item ( 8 butir) pertanyaan dalam kuesioner yang digunakan sebagai alat ukur variabel kinerja $(\mathrm{Y})$ ternyata semua item pertanyaan memiliki nilai diatas batas kritis yang ditentukan, sehingga semua item dinyatakan valid. Secara terperinci nilai dari masing-masing item dapat dilihat pada tabel berikut ini: 
Tabel 3.2

Hasil Uji Validitas Motivasi (X2)

\begin{tabular}{|c|c|c|}
\hline $\begin{array}{c}\text { Butir } \\
\text { pertanyaan }\end{array}$ & $\begin{array}{c}\text { Corrected } \\
\text { Item total Correlation }\end{array}$ & Status \\
\hline Butir 1 & 0,696 & Valid \\
\hline Butir 2 & 0,662 & Valid \\
\hline Butir 3 & 0,727 & Valid \\
\hline Butir 4 & 0,659 & Valid \\
\hline Butir 5 & 0,796 & Valid \\
\hline Butir 6 & 0,631 & Valid \\
\hline Butir 7 & 0,447 & Valid \\
\hline Butir 8 & 0,633 & Valid \\
\hline
\end{tabular}

Sumber : Data diolah 2020

Untuk Variabel Kinerja (Y), hasil dari uji validitas yang telah dilakukan menunjukkan bahwa dari seluruh item (6 butir) pertanyaan dalam kuesioner yang digunakan sebagai alat ukur variabel kinerja (Y) ternyata semua item pertanyaan memiliki nilai diatas batas kritis yang ditentukan, sehingga semua item dinyatakan valid. Secara terperinci nilai dari masing-masing item dapat dilihat pada tabel berikut ini:

Tabel 3.3

\begin{tabular}{|c|c|c|}
\hline $\begin{array}{c}\text { Butir } \\
\text { pertanyaan }\end{array}$ & $\begin{array}{c}\text { Corrected } \\
\text { Item total Correlation }\end{array}$ & Status \\
\hline Butir 1 & 0,704 & Valid \\
\hline Butir 2 & 0,652 & Valid \\
\hline Butir 3 & 0,661 & Valid \\
\hline Butir 4 & 0,693 & Valid \\
\hline Butir 5 & 0,605 & Valid \\
\hline Butir 6 & 0,747 & Valid \\
\hline
\end{tabular}

Sumber : Data diolah 2020

\section{b. Uji Reliabilitas}

Pengujian reliabilitas data dilakukan untuk mengetahui sejauh mana suatu pengukur dapat menunjukkan akurasi dan konsistensi butir pertanyaan. Untuk menguji reliabilitas data digunakan pengukur Cronbach Alpha. Menurut Sugiyono (2012:458) bahwa, "Cronbach Alpha merupakan salah satu koefisien reliabilitas yang paling sering digunakan". Skala pengukuran yang reliabel sebaiknya memiliki nilai
Cronbach Alpha minimal 0,60.

Uji Reliabilitas digunakan untuk membuktikan bahwa pernyataanpernyataan didalam kuesioner konsisten atau tidak. Uji Reliabilitas ini berkaitan dengan konsistensinya suatu data apabila dilakuan pengamatan berulang. Reliabilitas dalam penelitian ini diuji dengan menggunakan uji Cronbach Alfa, dengan ketentuan apabila nilai Cronbach Alpha > 0,6 maka instrument pengukuran reliable. Dari hasil perhitungan reliabilitas dapat dijelaskan bahwa seluruh 
item pernyataan dari masing-masing variabel adalah realibel.

- Realibilitas Variabel Disiplin Kerja $\left(\mathrm{X}_{1}\right)$

Hasil perhitungan nilai reliabilitas Cronbach Alpa untuk variabel disiplin kerja dengan bantuan SPSS 25 adalah sebesar 0,883 Artinya dari 6 item pernyataan yang dijadikan sebagai indikator pada variabel disiplin kerja $\left(\mathrm{X}_{1}\right)$ sudah reliabel.

- Realibilitas Variabel Motivasi $\left(\mathrm{X}_{2}\right)$

Hasil perhitungan nilai reliabilitas Cronbach Alpa untuk variabel motivasi dengan bantuan SPSS 25 adalah sebesar $\mathbf{0 , 8 8 6}$ Artinya dari 8 item pernyataan yang dijadikan sebagai indikator pada variabel motivasi $\left(\mathrm{X}_{2}\right)$ sudah reliabel

- Realibilitas Variabel Kinerja (Y)

Hasil perhitungan nilai reliabilitas Cronbach Alpa untuk variabel kinerja dengan bantuan SPSS 25 adalah sebesar 0,874 Artinya dari 6 item pernyataan yang dijadikan sebagai indikator pada variabel kinerja (Y) sudah reliabel.

Hasil uji realibilitas secara lebih terperinci dapat dilihat pada tabel berikut ini :

Tabel 3.4

Hasil Uji Reliabilitas

\begin{tabular}{|l|c|c|}
\hline \multicolumn{1}{|c|}{ Variabel } & $\begin{array}{c}\text { Alpha } \\
\text { Cronbach }(\boldsymbol{\alpha})\end{array}$ & Status \\
\hline Disiplin Kerja & $\mathbf{0 , 8 8 3}$ & Reliabel \\
\hline Motivasi & $\mathbf{0 , 8 8 6}$ & Reliabel \\
\hline Kinerja & $\mathbf{0 , 8 7 4}$ & Reliabel \\
\hline
\end{tabular}

Sumber : Data diolah 2020

3.2. Analisis Deskriptif Statistik

a. Koefesien Diterminasi $\left(\mathbf{R}^{2}\right)$

Tabel 3.5

Model Summary

\begin{tabular}{|l|r|r|r|r|}
\hline Model & R & R Square & \multicolumn{1}{|c|}{$\begin{array}{c}\text { Adjusted } \mathrm{R} \\
\text { Square }\end{array}$} & $\begin{array}{c}\text { Std. Error of the } \\
\text { Estimate }\end{array}$ \\
\hline 1 &, $951^{\mathrm{a}}$ &, 905 &, 900 & 1,15090 \\
\hline
\end{tabular}

a. Predictors: (Constant), MOTIVASI, DISIPILIN

Besarnya angka kofesien ditermanasi 0,905 atau sama dengan 90,5\%. Angka tersebut berarti bahwa sebesar 90,5\% kinerja dapat dijelaskan dengan menggunakan variabel motivasi dan disiplin. Sedangkan sisanya 9,5\% (100\% - 90,5\%) dijelaskan oleh faktor-faktor lain yang tidak diteliti dalam penelitian ini. 


\section{b. Uji Regresi Berganda}

Tabel 3.6

Coefficients $^{\mathrm{a}}$

\begin{tabular}{|c|c|c|c|c|c|}
\hline \multirow[t]{2}{*}{ Model } & \multicolumn{2}{|c|}{ Unstandardized Coefficients } & \multirow{2}{*}{$\begin{array}{c}\text { Standardized } \\
\text { Coefficients } \\
\text { Beta }\end{array}$} & \multirow[t]{2}{*}{$\mathrm{t}$} & \multirow[t]{2}{*}{ Sig. } \\
\hline & B & Std. Error & & & \\
\hline (Constant) & 646 & 1,935 & & 334 & ,740 \\
\hline \multirow{2}{*}{$\begin{array}{l}\text { DISIPILIN } \\
\text { MOTIVASI }\end{array}$} & ,049 & ,086 & ,029 & 4,573 &, 570 \\
\hline & .725 & 039 & 940 & 18,511 & 000 \\
\hline
\end{tabular}

a. Dependent Variable: Kinerja

Persamaan regresi berganda adalah :

$\mathrm{Y}=\alpha+\beta_{1} \mathrm{X}_{1}+\beta_{2} \mathrm{X}_{2}$

$\mathrm{Y}=0,646+0,049 \mathrm{X}_{1}+0,725 \mathrm{X}_{2}$

Dimana :

$\mathrm{Y}=$ Kinerja Karyawan

$\mathrm{X}_{1}=$ Disiplin

$\mathrm{X}_{2}=$ Motivasi

Adapun pembahasan temuan penelitian terhadap hasil analisis tersebut adalah sebagai berikut:

- Hasil perhitungan menunjukkan bahwa koefisien regresi untuk disiplin $\left(\mathrm{X}_{1}\right)$ sebesar 0,049, koefisien regresi untuk motivasi $\left(\mathrm{X}_{2}\right)$ sebesar 0,725 dan juga menghasilkan nilai konstanta sisipan sebesar 0,646. Hasil perhitungan tersebut dapat di interpresstasikan sebagai berikut :

- Konstanta sebesar 0,646 menyatakan bahwa jika tidak ada peningkatan disiplin $\left(\mathrm{X}_{1}\right)$ dan motivasi $\left(\mathrm{X}_{2}\right)$ secara matematik $\mathrm{X}_{1}$ dan $\mathrm{X}_{2}$ adalah 0 , maka kinerja karyawan (Y) tetap sebesar 0,646 unit skor. Hal ini bisa dipahami karena masih banyak variabel-variabel lain yang tidak dimasukkan dalam penelitian ini.

- Dengan melihat besarnya koefisien regresi bahwa variabel $\left(\mathrm{X}_{1}\right)$ sebesar 0,049 atau sama dengan 4,9\% artinya kecenderungan proyeksi perubahan antara variabel disiplin $\left(\mathrm{X}_{1}\right)$ terhadap variabel kinerja karyawan (Y) menunjukkan bahwa setiap perubahan atau ningkatan variabel disiplin $\left(\mathrm{X}_{1}\right)$ sebesar satuan, maka mengakibatkan perubahan atau peningkatan pada variabel kinerja karyawan (Y) sebesar 0,049 atau sama dengan $4,9 \%$.

- Koefisien regresi variabel motivasi $\left(\mathrm{X}_{2}\right)$ sebesar 0,725 artinya kecenderungan proyeksi perubahan antara variabel motivasi $\left(\mathrm{X}_{2}\right)$ dengan kinerja karyawan (Y) menunjukkan bahwa setiap perubahan atau peningkatan motivasi $\left(\mathrm{X}_{2}\right)$ sebesar satuan akan mengakibatkan perubahan atau peningkatan pula pada kinerja karyawan (Y) sebesar 0,725 atau sama dengan

$72,5 \%$. 


\section{c. Uji-T (secara parsial)}

\section{Tabel 3.7}

\section{Coefficients ${ }^{a}$}

\begin{tabular}{|c|c|c|c|c|c|c|}
\hline \multirow[t]{2}{*}{ Mod } & & \multicolumn{2}{|c|}{ Unstandardized Coefficients } & \multirow{2}{*}{$\begin{array}{c}\text { Standardized } \\
\text { Coefficients } \\
\text { Beta }\end{array}$} & \multirow[t]{2}{*}{$\mathrm{t}$} & \multirow[t]{2}{*}{ Sig. } \\
\hline & & B & Std. Error & & & \\
\hline \multirow{3}{*}{1} & (Constant) & 646 & 1,935 & & ,334 & 740 \\
\hline & \multirow{2}{*}{$\begin{array}{l}\text { DISIPILIN } \\
\text { MOTIVASI }\end{array}$} & ,049 & ,086 & ,029 & 4,573 & ,570 \\
\hline & & ,725 & ,039 & ,940 & 18,511 & , 000 \\
\hline
\end{tabular}

- Pengujian variabel disiplin $\left(b_{1}\right)$ dengan hipotesis :

$$
\begin{aligned}
\mathrm{H}_{\mathrm{o}}= & \text { koefiesien regresi (disiplin) secara } \\
& \text { parsial tidak berpengaruh terhadap } \\
& \text { kinerja } \\
\mathrm{H}_{1}= & \text { koefiesien regresi (disiplin) secara } \\
& \text { parsial berpengaruh terhadap } \\
& \text { kinerja. }
\end{aligned}
$$

Berdasarkan hasil dari output $\mathrm{t}$ hitung diperoleh sebesar 4,573. Untuk mencari t tabel pada signifikansi 0,05 dengan derajat kebebasan $\mathrm{df}=\mathrm{n}-\mathrm{k}-1$ atau 46-2-1 $=43$ maka diperoleh nilai untuk $t$ tabel sebesar 2,016

Jika $\mathrm{t}_{\text {hitung }}<\mathrm{t}_{\text {tabel, }}$ maka Ho diterima

Jika $\mathrm{t}_{\text {hitung }}>\mathrm{t}_{\text {tabel }}$, maka $\mathrm{H}_{1}$ ditolak

Karena $t_{\text {hitung }}(4,573)>t_{\text {tabel }}(2,016)$, maka $\mathrm{H}_{\mathrm{o}}$ ditolak, $\mathrm{H}_{1}$ diterima, artinya bahwa disiplin secara parsial berpengaruh terhadap kinerja.
- Pengujian variabel motivasi $\left(\mathrm{b}_{2}\right)$ dengan hipotesis :

$$
\begin{aligned}
\mathrm{H}_{\mathrm{o}}= & \text { koefiesien regresi (motivasi) } \\
& \text { secara parsial tidak berpengaruh } \\
& \text { terhadap kinerja } \\
\mathrm{H}_{1}= & \text { koefiesien regresi (motivasi) secara } \\
& \text { parsial berpengaruh terhadap } \\
& \text { kinerja. }
\end{aligned}
$$

Berdasarkan hasil dari output $t$ hitung diperoleh sebesar 18,511. Untuk mencari $t$ tabel pada signifikansi 0,05 dengan derajat kebebasan $\mathrm{df}=\mathrm{n}-\mathrm{k}-1$ atau 46-2-1 = 43 maka diperoleh nilai untuk $t$ tabel sebesar 2,016

Jika $\mathrm{t}_{\text {hitung }}<\mathrm{t}_{\text {tabel, }}$, maka Ho diterima

Jika $\mathrm{t}_{\text {hitung }}>\mathrm{t}_{\text {tabel, }}$, maka $\mathrm{H}_{1}$ ditolak

Karena $\mathrm{t}$ hitung $(18,511)>\mathrm{t}$ tabel $(2,016)$, maka $\mathrm{H}_{0}$ ditolak, $\mathrm{H}_{1}$ diterima, artinya bahwa motivasi secara parsial berpengaruh terhadap kinerja 


\section{d. Uji F (Uji Simultan)}

ANOVA $^{a}$

\begin{tabular}{|rr|r|r|r|r|r|}
\hline Model & Sum of Squares & df & Mean Square & F & Sig. \\
\hline & Regression & 540,000 & 2 & 270,000 & 20,3838 &, $000^{\text {b }}$ \\
1 & Residual & 56,957 & 43 & 1,325 & & \\
& Total & 596,957 & 45 & & & \\
\hline
\end{tabular}

a. Dependent Variable: KINERJA

b. Predictors: (Constant), MOTIVASI, DISIPILIN

$\mathrm{H}_{0}: \mathrm{b}_{1}, \mathrm{~b}_{2}=0$, artinya secara bersamasama tidak terdapat pengaruh yang positif dan signifikan dari variabel bebas $\left(\mathrm{X}_{1}, \mathrm{X}_{2}\right) \quad$ yaitu disipilin dan motivasi terhadap kinerja sebagai variabel terikat $(\mathrm{Y})$.

$\mathrm{H}_{1}: \mathrm{b}_{1}, \mathrm{~b}_{2} \neq 0$, artinya secara bersamasama terdapat pengaruh yang positif dan signifikan dari variabel bebas $\left(\mathrm{X}_{1}, \mathrm{X}_{2}\right)$ yaitu disipilin dan motivasi terhadap kinerja sebagai variabel terikat $(\mathrm{Y})$.

Berdasarkan hasil dari output $\mathrm{F}$ hitung diperoleh sebesar 20,384. Untuk mencari $F$ tabel pada signifikansi 0,05 dengan derajat kebebasan $\mathrm{df}=\mathrm{n}-\mathrm{k}-1$ atau $46-2-1=43$ maka diperoleh nilai untuk $F$ tabel sebesar 3,214 .

Jika $\mathrm{F}_{\text {hitung }}<\mathrm{F}_{\text {tabel, }}$, maka Ho diterima

Jika $\mathrm{F}_{\text {hitung }}>\mathrm{F}_{\text {tabel, }}$ maka $\mathrm{H}_{1}$ ditolak

$$
\text { Karena } \mathrm{F} \text { hitung }(20,384)>\mathrm{F} \text { tabel }
$$
$(3,214)$, maka $\mathrm{H}_{\mathrm{o}}$ ditolak, $\mathrm{H}_{1}$ diterima, artinya bahwa motivasi dan disiplin kerja secara bersama berpengaruh terhadap kinerja.

\section{KESIMPULAN DAN SARAN 4.1. Kesimpulan}

Berdasarkan hasil analisis dan evaluasi data penelitian yang dilakukan maka peneliti mengambil kesimpulan sebagai berikut bahwa disiplin kerja dan motivasi berpengaruh positif dan signifikan terhadap kinerja karyawan CV. Indah Usaha Mandiri Palembang hal ini dapat dilihat dari hasil analisis statistik:

a. Koefesien Diterminasi $\left(\mathrm{R}^{2}\right)$

Dari hasil uji $\mathrm{R}$ Square $\left(\mathrm{R}^{2}\right)$ didapat nilai sebesar 0,905 atau $90,5 \%$, ini menjelaskan bahwa pengaruh dari variabel independen terhadap variabel dependen yaitu disiplin $\left(\mathrm{X}_{1}\right)$ dan motifasi $\left(\mathrm{X}_{2}\right)$ terhadap kinerja karyawan $\mathrm{CV}$. Indah Usaha Mandiri Palembang (Y) sebesar $90,5 \%$, sedangkan sisanya $9,5 \%$ dijelaskan variabel lain yang tidak dibahas dalam penelitian ini.

b. Uji t (secara parsial)

Berdasarkan uji $\mathrm{t}$ diperoleh t-hitung disiplin $\left(\mathrm{X}_{1}\right)$ sebesar 4,573 dan t-hitung motifasi $\left(\mathrm{X}_{2}\right)$ sebesar 18,511 serta $t$ tabel sebesar 2,58 berarti nilai t-hitung lebih besar dari nilai t-tabel , maka secara parsial disiplin $\left(\mathrm{X}_{1}\right)$ dan motifasi $\left(\mathrm{X}_{2}\right)$ berpengaruh terhadap kinerja karyawan $\mathrm{CV}$. Indah Usaha Mandiri Palembang (Y). 


\section{c. Uji f (secara simultan)}

Berdasarkan uji $f$ diperoleh nilai $f$ hitung sebesar 20,384 f-hitung dan f-tabel sebesar 3,214 berarti nilai f-hitung lebih besar dari nilai f-tabel dan nilai P-volue sebesar 0,000 artinya variabel disiplin $\left(\mathrm{X}_{1}\right)$ bersama-sama varibel motifasi $\left(\mathrm{X}_{2}\right)$ berpengaruh sangat signifikan terhadap kinerja karyawan $\mathrm{CV}$. Indah Usaha Mandiri Palembang (Y).

\subsection{Saran-saran}

a. Dalam usaha untuk meningkatkan disiplin kerja karyawan, maka disiplin yang timbul dari dalam diri sendiri hendaknya perlu diperhatikan pimpinan yaitu disiplin pimpinan itu sendiri karena karena hal tersebut menjadi ukuran bagi karyawan.

b. Memberikan motifasi kepada karyawan sebagai faktor yang dapat menimbulkan dorongan kepada karyawan untuk bekerja lebih baik lagi dalam meningkatkan kinerjanya.

c. Perlu ditingkatkan kerja sama dan saling membantu antara sesame karyawan untuk menimbulkan perasaan keterikatan satu sama lain dalam menjalankan tugas yang pada akhirnya dapat mendorong tingkat kedisiplinan karyawan itu sendiri.

d. Menciptakan hubungan yang harmonis antara sesama karyawan dan pimpinan merupakan faktor yang menentukan tingkat kedisiplinan karyawan.

\section{DAFTAR PUSTAKA}

Asmiarsih, Manajemen Sumber Daya Manusia, cetakan keenam, Ghalia, Jakarta, 2006.
Handoko, T Hani, Manajemen Personalia dan Sumbedaya Manusia. Edisi kedua. Cetakan ketujuh. BPFE. Yogyakarta. 2012.

Hasibuan, H Malayu, Manajemen Sumber Daya Manusia, Edisi revisi, Penerbit Bumi Aksara, Jakarta. 2016.

Harahap Sofyan, Sistem Pengawasan Manajemen, Cetakan ketiga, Quantum, Jakarta, 2004.

Mangkunegara, Anwar Prabu, Manajemen Sumber Daya Manusia Perusahaan, PT Remaja Rosdakarya, Bandung, 2016.

Bedjo Siswanto, Sastrohadiwiryo, Manajemen Tenaga Kerja Indonesia, Penerbit Bumi Aksara, Jakarta, 2012.

Robbins, Stephen P, Prinsip-prinsip Perilaku Organisasi, Edisi kelima, Jakarta: Penerbit Erlangga, Jakarta, 2002.

Supardi dan Anwar, Siagian, Manajemen Personalia dan Sumber Daya Manusia, Cetakan Kedua, Penerbit Bumi Aksara, Jakarta, 2004.

Sugiyono, Metode Penelitian Bisnis, Penerbit CV Alfabeta, Bandung. 2012.

Situmorang, Syafrizal Helmi, Iskandar Muda, Fauzie Syarief.. Analisis Data untuk Riset Riset Manajemen dan Bisnis. USU Press, Medan 2010.

Winardi, Manajemen Sumber Daya Manusia Untuk Perusahaan. Raja Grafindo, Jakarta, 2000. 